\title{
Low circulating ghrelin levels in women with polycystic ovary syndrome: a systematic review and meta-analysis
}

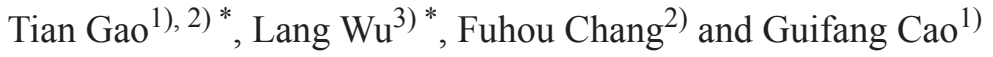 \\ 1) Department of Veterinary, Inner Mongolia Agricultural University, Hohhot, MO, 010018, People's Republic of China \\ 2) Center for safty evaluation of drugs, Inner Mongolia Medical University, Hohhot, MO, 010110, People's Republic of China \\ 3) Center for Clinical and Translational Science, Mayo Clinic, Rochester, Minnesota, 55905, USA
}

\begin{abstract}
Although numerous, human subject studies evaluating the relationship between circulating ghrelin levels and polycystic ovary syndrome (PCOS) risk have yielded inconsistent findings. We aimed to quantitatively assess the association by summarizing all available evidence from human subject studies. The PubMed and Web of Science databases were searched up to February 2015 for eligible studies. Studies were eligible if they reported circulating ghrelin levels in women with PCOS and healthy women controls. A fixed or random-effects model was used to pool risk estimations. Twenty studies including 894 PCOS patients and 574 controls were included in the meta-analysis. The studies had fair methodological quality. The pooling analysis of all available studies revealed that ghrelin levels were significantly lower in PCOS patients than in controls, with standardized mean difference of -0.40 (95\% CI: $-0.73,-0.08)$. The significant association persisted in many subgroup strata. However, the heterogeneity across studies was considerable and not eliminated in subgroup analyses. Meta-regression analysis further suggested that the heterogeneity might be relevant to variability in study location, PCOS relevant factors like HOMA-IR ratio, as well as other factors not assessed. In conclusion, our meta-analysis suggested that ghrelin levels were significantly lower in PCOS patients than in controls. Further studies with large sample sizes are warranted to replicate our findings.
\end{abstract}

Key words: Ghrelin level, Polycystic ovary syndrome, Meta-analysis

POLYCYSTIC OVARY SYNDROME (PCOS) remains one of the most common endocrinopathies [1]. In the United States, approximately 4 million women were affected with PCOS [2], with symptoms starting from adolescence to postmenopause [3]. Insulin resistance, dyslipidaemia, impaired glucose tolerance and diabetes occur frequently in PCOS women. Additionally, both young and elder PCOS patients have high risks of developing cardiovascular diseases $[4,5]$. Aligning with the public health burden, PCOS leads to a heavily economic burden. It is estimated that annually there is up to $\$ 4.36$ billion expense relevant to PCOS for the US health-care system [2]. To better clarify the etiology of PCOS is thus critical for decreasing burden from this disease. However, up to date, the

Submitted Jun. 22, 2015; Accepted Oct. 7, 2015 as EJ15-0318

Released online in J-STAGE as advance publication Nov. 26, 2015

Correspondence to: Guifang Cao, Department of Veterinary, Inner Mongolia Agricultural University, Hohhot, MO, 010018, People's Republic of China. E-mail: guifangcao@126.com

* TG and LW contribute equally to this study.

CThe Japan Endocrine Society exact etiology of PCOS has not been fully understood.

Ghrelin is a peptide hormone that plays a critical role in energy balance, food intake and weight regulation $[6,7]$. Research has shown a central and peripheral effect of ghrelin on insulin level $[8,9]$ and blood glucose homeostasis [10]. Ghrelin is demonstrated to be able to reverse the down-regulating effect of insulin on phosphoenolpyruvate carboxykinase, which is the rate-limiting enzyme of gluconeogenesis [8]. Considering a tight link between insulin, blood glucose and PCOS, ghrelin is hypothesized to be involved in the development of PCOS, which is evaluated in numerous human studies.

The first report that assessed the association between fasting ghrelin level and PCOS risk was mentioned by Schofl et al. [11] in which the fasting serum ghrelin levels were examined in a group of otherwise healthy women with PCOS and a group of healthy control subjects. They found that the circulating ghrelin level was lower in patients with PCOS. After that, Orio et al. [12] reported that no difference in plasma ghrelin level 
was detected in PCOS patients compared with weight matched controls. Such inconsistencies persisted in further studies evaluating the research question of interest. Although several reviews [13-16] have tried to summarize the topic, none of them was conducted systematically and none provided a quantitative evaluation. We thus conducted this meta-analysis to clarify the relationship between circulating ghrelin levels and PCOS risk by quantitatively pooling all findings from relevant studies.

\section{Materials and Methods}

\section{Literature search}

A comprehensive literature search of PubMed and Web of Science databases was conducted from the inception to February 19, 2015 for human studies published in English. The following MeSH terms and keywords were used:ghrelin AND ((polycystic ovary syndrome) OR PCOS). The references of involved articles were manually searched as well.

\section{Study selection criteria}

Studies were eligible if they (i) reported circulating ghrelin levels in women with PCOS and healthy women controls; (ii) provided ghrelin means (M) and standard deviation (SD) or sufficient information to calculate them. Papers with no relevance to our research question, such as reviews, letters, editorials, animal or cell line studies, studies without healthy controls, as well as studies regarding genetic variation in ghrelin-related genes were excluded. Additionally, studies in which patients were with a disease other than PCOS, as well as studies involving pregnant patients or patients with medication treatments were also excluded.

\section{Data extraction}

The following information was extracted from each included study: (i) characteristics of participants including body mass index (BMI), age, ethnicity and diagnosis methods etc; (ii) the type of blood sample (serum or plasma); (iii) methods of measuring ghrelin levels (radioimmunoassay (RIA) or enzyme-linked immunosorbent assay (EIA)).

\section{Quality assessment of included studies}

Quality evaluation of included studies was conducted with the Newcastle-Ottawa Scale (NOS) [17]. The quality assessment criteria used in the current study were: 1 . whether the diagnosis of the PCOS was with independent validation; 2 . whether the involved cases were representative; 3 . whether the controls enrolled were from the same community; 4 . whether the controls were described to have no history of PCOS; 5. whether the cases and controls were matched or adjusted for age or BMI ; 6 . Whether at least one additional factor, such as drinking or smoking status were matched or adjusted for cases and controls; 7. whether the ascertainment of exposure was under blind measurement; 8 . whether the test methods were the same for cases and controls; 9. whether the response rates for cases and controls were the same. For each criterion a score of 0 or 1 was assigned according to whether the criterion was satisfactorily fulfilled. The maximum possible score for an individual study is 9. Studies with scores of 7 or above are categorized as high quality studies. Others are categorized as low quality studies.

\section{Statistical methods}

The summary standardized mean difference (SMD) with $95 \%$ confidence intervals (CIs) was determined for circulating ghrelin levels in PCOS cases versus controls. $\mathrm{I}^{2}$ was used to assess the heterogeneity across studies, where a $\mathrm{I}^{2}>50 \%$ suggests considerable heterogeneity $[18,19]$. We pooled the estimates using the fixed-effects model [20] when there was no considerable heterogeneity. Otherwise, we used the randomeffects model [21] when there was high heterogeneity.

Subgroup analyses were conducted based on subject age ( $\geq 20$ years or $<20$ years), blood sample type (plasma or serum), methods of measuring ghrelin levels (RIA or EIA), BMI ( $<25, \geq 25$ or unknown), Homeostasis model assessment of insulin resistance (HOMA-IR) ratio $(<1.36,1.36-1.7,1.71-2.12,>2.12$, not reported), total testosterone ratio (T-ratio) $(<1.68$, $1.68-2.49,>2.5$ or not reported), study quality (high or low) and geographic location (America, Europe, Asia, Australia or Turkey). Furthermore, we performed meta-regression analyses incorporating relevant factors to assess potential sources of heterogeneity. We also evaluated heterogeneities when focusing only on PCOS cases or controls across studies.

Publication bias was evaluated via Egger's test [22] and Begg's test [23]. A $P$-value of 0.05 was used as the threshold to determine significant publication bias. All statistical analyses were performed with Stata (version 13; StataCorp, College Station, TX). 


\section{Results}

\section{Literature search and study characteristics}

The detailed steps of the literature search were demonstrated in Fig. 1. A total of 20 reports that met the inclusion criteria were included in this study [11, 24-41]. Since several studies reported the estimates separately according to different categories of BMI $(<25$ or $\geq 25)$, we treated them as from separate studies and incorporated all in the pooling analysis $[25,26,30$, $32,35,41]$. The detailed characteristics of the included studies were demonstrated in Table 1. In total, all studies evaluated the circulating ghrelin levels in PCOS cases versus controls. In all studies samples were collected after overnight fast. In 14 studies serum samples were used to measure ghrelin levels and in other 6 studies plasma samples were used. Ghrelin levels were measured by RIA in 13 studies and by EIA assay in 7 studies. Eleven studies reported the HOMA-IR information and 15 studies reported the T-ratio information. Overall, 8 studies were conducted in Europe, 1 in America, 4 in Asia, 2 in Australia and 5 in Turkey. The involved studies enrolled 894 PCOS patients and 574 controls. The detailed quality ratings for each study were listed in Table 2. Overall, the studies had fair methodological quality. Eleven studies scored 7 or above and were categorized as high quality studies; 9 studies were categorized as low quality ones.

For 16 included studies [12, 24-29, 31-34, 36-39, 41], the diagnosis of PCOS was based on the revised 2003 consensus on diagnostic criteria of PCOS by Rotterdam ESHRE/ASRM-Sponsored PCOS Consensus Workshop Group [42]. In these studies all PCOS patients met at least 2 of the required 3 cri- teria as: 1). oligo- or anovulation; 2). clinical and/or biochemical signs of hyperandrogenism; 3 ). polycystic ovaries and exclusion of other etiologies (congenital adrenal hyperplasia, androgen-secreting tumors, Cushing's syndrome) [42]. For 3 other included studies $[11,35,40]$, the diagnosis of PCOS was confirmed by relevant clinical symptoms and laboratory findings. For example, for Wasko et al. [42], the presence of oligomenorrhea or secondary amenorrhea, hyperandrogenemia or clinical evidence of hyperandrogenism was evaluated. For Schofl et al. [11], the diagnosis criteria included clinical symptoms like oligomenorrhea and hirsutism as well as laboratory findings of elevated serum androgen levels and/or elevated LH/FSH ratio. For Ozgen et al. [35], adolescents were diagnosed as PCOS if any four of the five criteria were met: oligomenorrhea or amenorrhea existence after two years of menarche; clinical hyperandrogenism; biologic hyperandrogenism; insulin resistance, hyperinsulinism; and microcysts in ovaries or increased ovarian size. The diagnosis criteria in Shi et al. were not specified [30].

\section{Meta-analysis}

The pooling analysis of all available studies revealed that ghrelin levels were significantly lower in PCOS patients than in controls, with SMD of -0.40 (95\% CI: $-0.73,-0.08$ ) (Table 3). This relationship was also detected when focusing only on studies with adult participants (at least 20 years old) (Table 3). Considerable heterogeneity across studies was detected $\left(\mathrm{I}^{2}=86.7 \%\right)$ (Table 3; Fig. 2). Begg's test and Egger's test did not suggest significant publication bias ( $p$ for bias: 0.402 and 0.193, respectively). Subgroup analyses demonstrated that the finding of lower ghrelin levels in PCOS

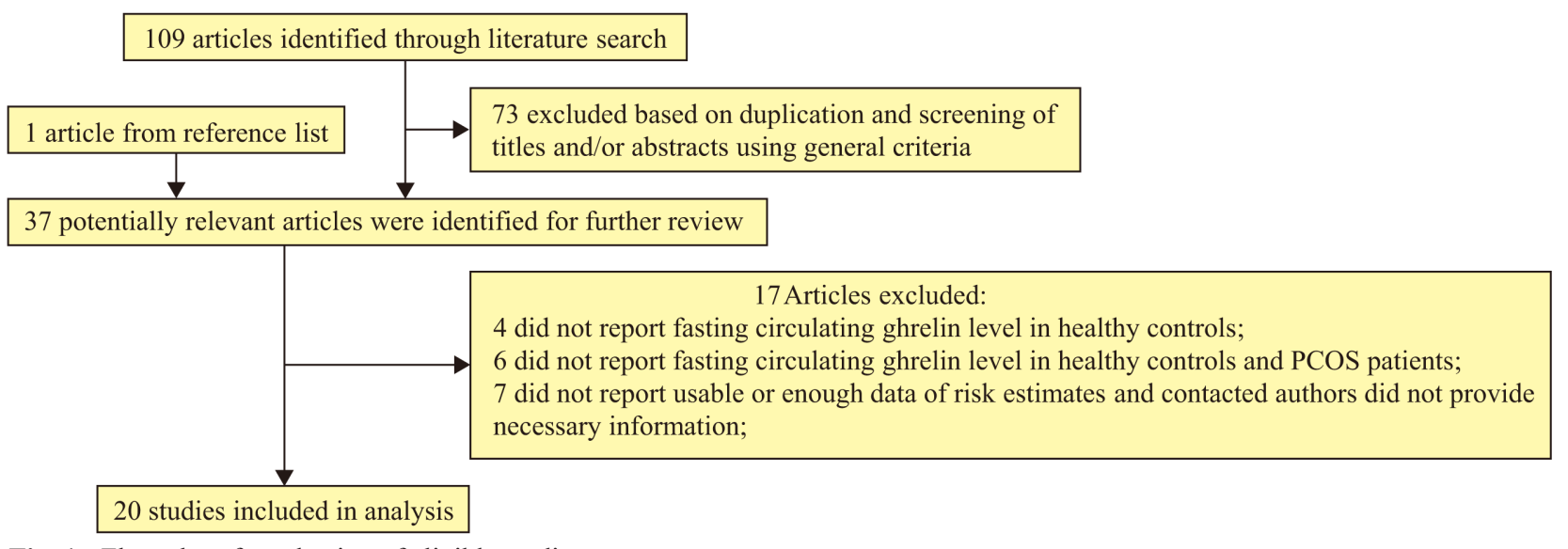

Fig. 1 Flow chart for selection of eligible studies 
Table 1 Main characteristics of studies included in the meta-analysis

\begin{tabular}{|c|c|c|c|c|c|c|c|c|c|c|c|c|c|c|}
\hline \multirow{3}{*}{$\begin{array}{l}\text { Study } \\
\text { Arusoglu }\end{array}$} & \multirow{3}{*}{$\begin{array}{l}\text { Year } \\
2013\end{array}$} & \multirow{3}{*}{$\begin{array}{l}\text { Region } \\
\text { Turkey }\end{array}$} & \multirow{3}{*}{$\begin{array}{c}\text { Method } \\
\text { RIA }\end{array}$} & \multirow{3}{*}{$\begin{array}{l}\text { Blood } \\
\text { Sample } \\
\text { Serum }\end{array}$} & \multirow{3}{*}{$\begin{array}{l}\begin{array}{l}\text { BMI } \\
\left(\mathrm{kg} / \mathrm{m}^{2}\right)\end{array} \\
<25\end{array}$} & \multirow{2}{*}{\multicolumn{2}{|c|}{$\begin{array}{c}\text { Sample size } \\
\text { PCOS Controls }\end{array}$}} & \multicolumn{2}{|c|}{ Age $($ mean $\pm \mathrm{SD}$, year $)$} & \multicolumn{2}{|c|}{ Ghrelin (mean \pm SD) } & \multirow{2}{*}{$\begin{array}{c}\text { HOMA-IR } \\
\text { ratio }\end{array}$} & \multirow{2}{*}{ T-ratio } & \multirow{2}{*}{$\begin{array}{c}\text { SMD } \\
(95 \% \text { CI })\end{array}$} \\
\hline & & & & & & & & PCOS & Controls & PCOS & Controls & & & \\
\hline & & & & & & 18 & 18 & $22.1 \pm 4.2$ & $21.7 \pm 3.4$ & $845 \pm 280 \mathrm{pg} / \mathrm{mL}$ & $1051 \pm 494 \mathrm{pg} / \mathrm{mL}$ & 1.79 & NR - & $-0.51(-1.18,0.15)$ \\
\hline \multirow{2}{*}{ Bideci } & \multirow{2}{*}{2008} & \multirow{2}{*}{ Turkey } & \multirow{2}{*}{ RIA } & \multirow{2}{*}{ plasma } & $<25$ & 12 & \multirow[b]{2}{*}{9} & $15.1 \pm 0.8$ & \multirow{2}{*}{$14.8 \pm 1.0$} & $39.4 \pm 4.4 \mathrm{ng} / \mathrm{mL}$ & \multirow{2}{*}{$36.7 \pm 4.1 \mathrm{ng} / \mathrm{mL}$} & \multirow{2}{*}{ NR } & NR & $0.64(-0.10,1.38)$ \\
\hline & & & & & $\geq 25$ & 16 & & $15.2 \pm 0.8$ & & $33.9 \pm 3.2 \mathrm{ng} / \mathrm{mL}$ & & & NR - & $-0.75(-1.44,-0.06)$ \\
\hline pur & 2014 & Brazil & RIA & plasma & $\geq 25$ & 30 & 23 & $29.1 \pm 5.8$ & $33.2 \pm 5.4$ & $542.9 \pm 142.6 \mathrm{pg} / \mathrm{mL}$ & $600.3 \pm 224.6 \mathrm{pg} / \mathrm{mL}$ & 1.25 & 1.68 & $-0.31(-0.86,0.23)$ \\
\hline \multirow{2}{*}{ Cassar } & \multirow{2}{*}{2014} & \multirow{2}{*}{ Australia } & \multirow{2}{*}{ EIA } & \multirow{2}{*}{ Serum } & $<25$ & 22 & 22 & $27 \pm 4$ & $28 \pm 6$ & $0.25 \pm 0.07 \mathrm{ng} / \mathrm{mL}$ & $0.25 \pm 0.05 \mathrm{ng} / \mathrm{mL}$ & NR & 1.24 & $0.00(-0.59,0.59)$ \\
\hline & & & & & $\geq 25$ & 22 & 18 & $29 \pm 4$ & $35 \pm 5$ & $0.17 \pm 0.08 \mathrm{ng} / \mathrm{mL}$ & $0.16 \pm 0.07 \mathrm{ng} / \mathrm{mL}$ & $\mathrm{R}$ & 1.79 & $0.13(-0.49,0.76)$ \\
\hline aghestani & 2011 & $\begin{array}{l}\text { Saudi } \\
\text { Arabia }\end{array}$ & EIA & Serum & $\geq 25$ & 30 & 30 & $7.22 \pm 3.29$ & $26.05 \pm 6.08$ & $0.42+0$ & $0.43 \pm 0.11 \mathrm{ng} / \mathrm{mL}$ & NR & 2.24 & $-0.09(-0)$ \\
\hline Houjeghani & 2011 & Iran & RIA & plasma & & 30 & 30 & $25.83 \pm 4$ & $26.06 \pm 4.44$ & $210.33 \pm 58.5 \mathrm{pmol} / \mathrm{L}$ & $216 \pm 80.84 \mathrm{pmol} / \mathrm{L}$ & 1.92 & 1.67 & $-0.08(-0.59,0.43)$ \\
\hline ahde & 2009 & Iraq & EIA & serum & $\geq 25$ & 60 & 30 & $26.45 \pm 4.65$ & $28.87 \pm 3.27$ & $138.22 \pm 58.40 \mathrm{pg} / \mathrm{mL}$ & $169.67 \pm 25.51 \mathrm{pg} / \mathrm{mL}$ & NR & 1.22 & $-0.63(-1.08,-0.18)$ \\
\hline \multirow{2}{*}{ Micic } & \multirow{2}{*}{2007} & & & & $<25$ & 8 & 8 & $22.12 \pm 8.06$ & $24.87 \pm 19.54$ & $64.74 \pm 72.66 \mathrm{pg} / \mathrm{mL}$ & $108.36 \pm 148.78 \mathrm{pg} / \mathrm{mL}$ & 1.26 & 1.86 & $-0.37(-1.36,0.62)$ \\
\hline & & & & serum & $\geq 25$ & 8 & 8 & $25.06 \pm 18.02$ & $28.50 \pm 14.09$ & $38.71 \pm 40.11 \mathrm{pg} / \mathrm{mL}$ & $98.77 \pm 114.52 \mathrm{pg} / \mathrm{mL}$ & 2.11 & 2.32 & $-0.70(-1.71,0.31)$ \\
\hline Gitkov & 2008 & Bulgaria & EIA & serum & & 45 & 20 & $23.27 \pm 5.1$ & $25.35 \pm 4.2$ & $21.78 \pm 14.22 \mathrm{ng} / \mathrm{mL}$ & $78.33 \pm 18.16 \mathrm{ng} / \mathrm{mL}$ & 1.69 & 1.78 & $-3.65(-4.47,-2.82)$ \\
\hline Moran & 2007 & Australia & EIA & serum & $\geq 25$ & 13 & 13 & $32.3 \pm 21.27$ & $36.2 \pm 16.22$ & $486.2 \pm 148.18 \mathrm{pg} / \mathrm{mL}$ & $318.1 \pm 158.64 \mathrm{pg} / \mathrm{mL}$ & NR & NR & $1.10(0.27,1.92)$ \\
\hline rio & 2003 & 1 & RIA & plasma & $\geq 25$ & 33 & 32 & $26.1 \pm 7.9$ & $29.6 \pm 6.9$ & $179 \pm 155.1 \mathrm{pmol} / \mathrm{L}$ & $181 \pm 135.76 \mathrm{pmol} / \mathrm{L}$ & 1.94 & 3.67 & $-0.01(-0.50,0.47)$ \\
\hline & & & & & $<25$ & 13 & 10 & $15.45 \pm 1.26$ & $15.37 \pm 0.96$ & $1244.5 \pm 289.4 \mathrm{pg} / \mathrm{mL}$ & $1172.9 \pm 393.6 \mathrm{pg} / \mathrm{mL}$ & 1.16 & 1.63 & $0.21(-0.62,1.04)$ \\
\hline Ozgen & 2010 & Turkey & RIA & serum & $\geq 25$ & 13 & 10 & $14.9 \pm 0.9$ & $14.98 \pm 1.55$ & $888.7 \pm 330.4 \mathrm{pg} / \mathrm{mL}$ & $1020.4 \pm 226 \mathrm{pg} / \mathrm{mL}$ & 1.7 & 1.34 & $-0.45(-1.29,0.38)$ \\
\hline anidis & 2005 & Greece & EIA & plasma & & 259 & 46 & $23.04 \pm 5.12$ & $28.33 \pm 5.94$ & $513.58 \pm 294.96 \mathrm{pmol} / \mathrm{L}$ & $563.8 \pm 226.71 \mathrm{pmol} / \mathrm{L}$ & 1.45 & 1.88 & $-0.18(-0.49,0.14)$ \\
\hline Panidis & 2010 & Greece & RIA & serum & $<25$ & 50 & 10 & $23.70 \pm 4.99$ & $30.50 \pm 5.80$ & $309.4 \pm 99.8 \mathrm{pmol} / \mathrm{L}$ & $334.3 \pm 120.3 \mathrm{pmol} / \mathrm{L}$ & 0.84 & 1.97 & $-0.24(-0.92,0.44)$ \\
\hline hofl & 2002 & Germany & RIA & serum & & 26 & 61 & $28.7 \pm 5.1$ & $28.9 \pm 5.47$ & $181 \pm 71.39 \mathrm{pmol} / \mathrm{L}$ & $224 \pm 112 \mathrm{pmol} / \mathrm{L}$ & NR & NR & $-0.42(-0.89,0.04)$ \\
\hline Shi & & & & & $<25$ & 30 & 20 & $27.18 \pm 4.66$ & & $2761.36 \pm 1628.9 \mathrm{pg} / \mathrm{mL}$ & & & 1.83 & $0.31(-0.26,0.88)$ \\
\hline Sh1 & 2011 & & EIA & & $\geq 25$ & 27 & 20 & $25.10 \pm 3.26$ & & $2195.97 \pm 1378.8 \mathrm{pg} / \mathrm{mL}$ & & & 1.87 & $-0.07(-0.65,0.51)$ \\
\hline Temel & 2010 & Turkey & RIA & serum & $<25$ & 30 & 30 & $23.13 \pm 4.28$ & $23.3 \pm 2.76$ & $815 \pm 323 \mathrm{pg} / \mathrm{mL}$ & $1459 \pm 306 \mathrm{pg} / \mathrm{mL}$ & 1.82 & 1.37 & $-2.05(-2.68,-1.42)$ \\
\hline $\begin{array}{l}\text { Kale- } \\
\text { Gurbuz }\end{array}$ & 2013 & Turkey & RIA & Serum & $\geq 25$ & 17 & 21 & $18.17 \pm 1.62$ & $17.52 \pm 1.16$ & $665.69 \pm 402.12 \mathrm{ng} / \mathrm{mL}$ & $650.22 \pm 467.73 \mathrm{ng} / \mathrm{mL}$ & 0.9 & 2.42 & $0.04(-0.60,0.67)$ \\
\hline Wasko & 2004 & Poland & RIA & serum & & 42 & 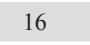 & $22.88 \pm 4.49$ & $25.7 \pm 8.02$ & $354.38 \pm 167.77 \mathrm{pmol} / \mathrm{L}$ & $232.66 \pm 86.93 \mathrm{pmol} / \mathrm{L}$ & NR & NR & $0.81(0.21,1.40)$ \\
\hline & & & & & $<25$ & 19 & & $22 \pm 2.5$ & & $852 \pm 79 \mathrm{pg} / \mathrm{mL}$ & & 1.7 & 1.42 & $-0.18(-0.81,0.45)$ \\
\hline & 2008 & & KIA & & $\geq 25$ & 21 & & $21 \pm 2.9$ & & $617 \pm 73$ & & 2.56 & 1.63 & $-4.15(-5.26,-3.04)$ \\
\hline
\end{tabular}

T-ratio, total testosterone ratio; SMD, standardized mean difference.

Table 2 Quality Assessment of Included Studies

\begin{tabular}{|c|c|c|c|c|c|c|c|c|c|}
\hline$\overline{\text { Study }}$ & $\begin{array}{l}\text { Case defined } \\
\text { with independent } \\
\text { validation }\end{array}$ & $\begin{array}{l}\text { Representativeness } \\
\text { of the cases }\end{array}$ & $\begin{array}{l}\text { Selection of } \\
\text { controls from } \\
\text { community }\end{array}$ & $\begin{array}{l}\text { Statement that } \\
\text { controls have no } \\
\text { history of outcome }\end{array}$ & $\begin{array}{l}\text { Cases and controls } \\
\text { matched and/or } \\
\text { adjusted by factors }\end{array}$ & $\begin{array}{l}\text { Ascertain exposure } \\
\text { by blinded structured } \\
\text { interview }\end{array}$ & $\begin{array}{l}\text { Same method of } \\
\text { ascertainment for cases } \\
\text { and controls }\end{array}$ & $\begin{array}{l}\text { Same response } \\
\text { rate for both } \\
\text { groups }\end{array}$ & $\begin{array}{l}\text { Overall } \\
\text { score }\end{array}$ \\
\hline Arusoglu, 2013 [24] & 1 & 1 & 0 & 1 & 2 & 0 & 1 & 1 & 7 \\
\hline Bideci, 2008 [25] & 1 & 0 & 0 & 1 & 1 & 0 & 1 & 1 & 5 \\
\hline Cassar, 2014 [26] & 1 & 1 & 1 & 1 & 2 & 0 & 1 & 1 & 8 \\
\hline Daghestani, 2011 [27] & 1 & 0 & 1 & 1 & 2 & 0 & 1 & 1 & 7 \\
\hline Houjeghani, 2011 [38] & 1 & 1 & 1 & 1 & 2 & 0 & 1 & 1 & 8 \\
\hline Japur, 2014 [28] & 1 & 1 & 0 & 1 & 2 & 0 & 1 & 1 & 7 \\
\hline Kale-Gurbuz, 2013 [29] & 1 & 1 & 1 & 0 & 2 & 0 & 1 & 1 & 7 \\
\hline Mahde, 2009 [31] & 1 & 0 & 0 & 0 & 2 & 0 & 1 & 1 & 5 \\
\hline Micic, 2007 [32] & 1 & 0 & 0 & 1 & 2 & 0 & 1 & 1 & 6 \\
\hline Mitkov, 2008 [33] & 1 & 1 & 0 & 1 & 2 & 0 & 1 & 1 & 7 \\
\hline Moran, 2007 [34] & 1 & 1 & 1 & 0 & 2 & 0 & 1 & 1 & 7 \\
\hline Orio, 2003 [12] & 1 & 0 & 0 & 1 & 2 & 0 & 1 & 1 & 6 \\
\hline Ozgen, 2010 [35] & 1 & 0 & 0 & 0 & 2 & 0 & 1 & 1 & 5 \\
\hline Panidis, 2005 [37] & 1 & 0 & 0 & 1 & 1 & 0 & 1 & 1 & 5 \\
\hline Panidis, 2010 [36] & 1 & 0 & 0 & 1 & 1 & 0 & 1 & 1 & 5 \\
\hline Schöfl, 2002 [11] & 1 & 0 & 0 & 1 & 1 & 0 & 1 & 1 & 5 \\
\hline Shi, 2011 [30] & 0 & 0 & 1 & 1 & 1 & 0 & 1 & 1 & 5 \\
\hline Temel, 2010 [39] & 1 & 0 & 1 & 1 & 2 & 0 & 1 & 1 & 7 \\
\hline Wasko, 2004 [40] & 1 & 0 & 0 & 1 & 1 & 0 & 1 & 1 & 5 \\
\hline Zwirska-Korczala, 2008 [41] & 1 & 1 & 1 & 1 & 1 & 0 & 1 & 1 & 7 \\
\hline
\end{tabular}

1 means study adequately fulfilled a quality criterion ( 2 for case-control fully matched and adjusted), 0 means it did not. Quality scale does not imply that items are of equal relevant importance. 
Table 3 Summary risk estimates of circulating ghrelin levels and polycystic ovary syndrome (PCOS)

\begin{tabular}{|c|c|c|c|c|}
\hline & No of reports & Random-effects SMD $(95 \% \mathrm{CI})$ & $\mathrm{I}^{2}(\%)$ & $P$ for heterogeneity \\
\hline Overall & 26 & $-0.40(-0.73,-0.08)$ & 86.7 & $<0.001$ \\
\hline \multicolumn{5}{|l|}{ Subgroup analysis } \\
\hline \multicolumn{5}{|l|}{ Age } \\
\hline Adult ( $\geq 20$ y) & 21 & $-0.49(-0.87,-0.10)$ & 88.8 & $<0.001$ \\
\hline Adolescent $(<20 \mathrm{y})$ & 5 & $-0.07(-0.55,0.42)$ & 53.8 & 0.070 \\
\hline \multicolumn{5}{|l|}{ BMI } \\
\hline$<25$ & 9 & $-0.25(-0.78,0.28)$ & 81.5 & $<0.001$ \\
\hline$\geq 25$ & 12 & $-0.42(-0.87,0.04)$ & 83.7 & $<0.001$ \\
\hline unknown & 5 & $-0.66(-1.64,0.32)$ & 94.9 & $<0.001$ \\
\hline \multicolumn{5}{|l|}{ Study quality } \\
\hline High & 14 & $-0.77(-1.45,-0.08)$ & 92.7 & $<0.001$ \\
\hline Low & 12 & $-0.12(-0.36,0.12)$ & 54.4 & 0.008 \\
\hline \multicolumn{5}{|l|}{ Location } \\
\hline Europe & 10 & $-0.84(-1.56,-0.13)$ & 92.8 & $<0.001$ \\
\hline America & 1 & $-0.31(-0.86,0.23)$ & - & - \\
\hline Asia & 5 & $-0.14(-0.45,0.17)$ & 43.5 & 0.132 \\
\hline Australia & 3 & $0.35(-0.25,0.95)$ & 58.3 & 0.091 \\
\hline Turkey & 7 & $-0.42(-1.10,0.25)$ & 84.4 & $<0.001$ \\
\hline \multicolumn{5}{|l|}{ Blood sample } \\
\hline Plasma & 8 & $-0.51(-1.08,0.06)$ & 87.7 & $<0.001$ \\
\hline Serum & 18 & $-0.35(-0.78,0.07)$ & 87.1 & $<0.001$ \\
\hline \multicolumn{5}{|c|}{ Method of measurement } \\
\hline RIA & 17 & $-0.45(-0.86,-0.04)$ & 84.5 & $<0.001$ \\
\hline EIA & 9 & $-0.32(-0.91,0.27)$ & 90.5 & $<0.001$ \\
\hline \multicolumn{5}{|l|}{ HOMA-IR ratio } \\
\hline$<1.36$ & 5 & $-0.15(-0.46,0.16)$ & 0.0 & 0.796 \\
\hline $1.36-1.7$ & 4 & $-1.09(-2.45,0.28)$ & 95.1 & $<0.001$ \\
\hline $1.71-2.12$ & 5 & $-0.66(-1.42,0.10)$ & 86.6 & $<0.001$ \\
\hline$>2.12$ & 1 & $-4.15(-5.26,-3.04)$ & - & - \\
\hline not reported & 11 & $0.05(-0.27,0.38)$ & 70.1 & $<0.001$ \\
\hline \multicolumn{5}{|l|}{ T-ratio } \\
\hline$<1.68$ & 8 & $-0.85(-1.59,-0.12)$ & 90.5 & $<0.001$ \\
\hline $1.68-2.49$ & 11 & $-0.43(-0.91,0.06)$ & 86.2 & $<0.001$ \\
\hline$>2.5$ & 1 & $-0.01(-0.50,0.47)$ & - & - \\
\hline not reported & 6 & $0.12(-0.49,0.73)$ & 81.3 & $<0.001$ \\
\hline
\end{tabular}

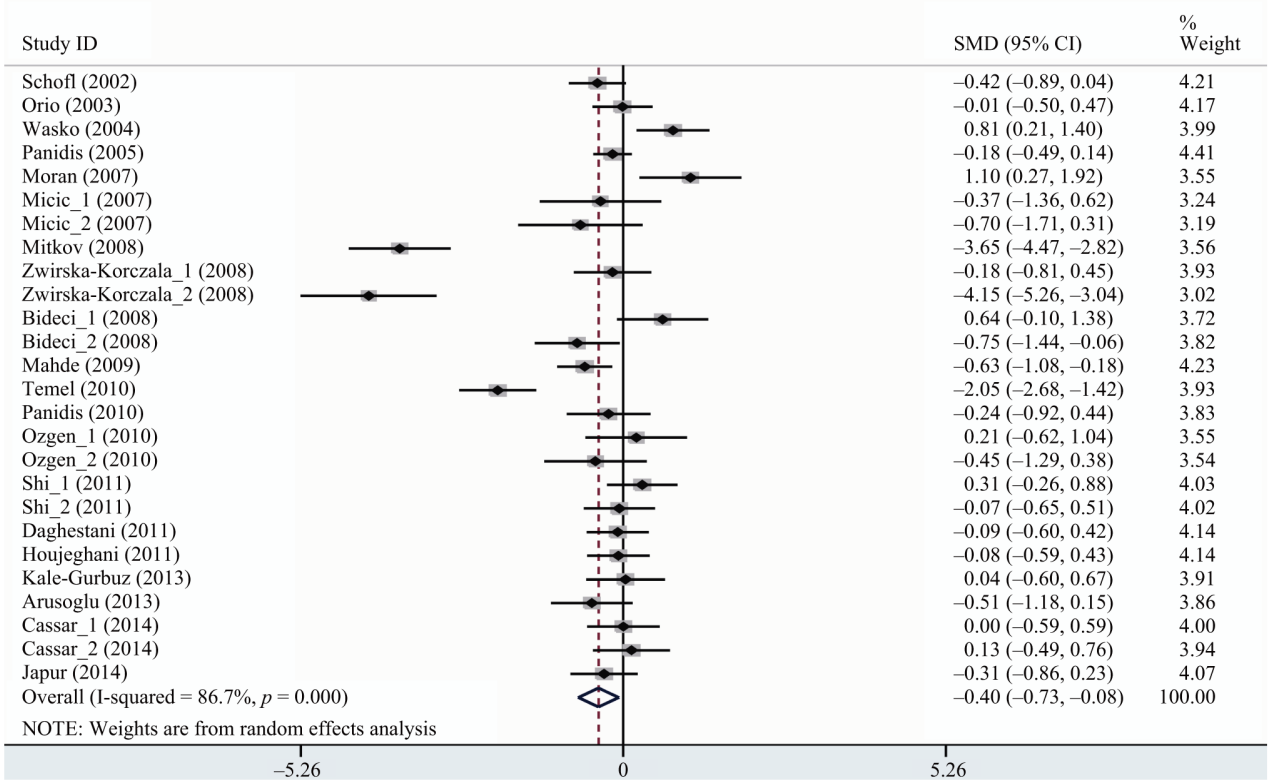

Fig. 2 Forest plot (random effects model) of circulating ghrelin levels and polycystic ovary syndrome (PCOS) 
patients was also detected in many strata. For example, the finding was identified in studies of high quality, studies conducted in Europe, studies in which the measuring method was RIA, as well as studies with HOMA-IR ratio of larger than 2.12 and T-ratio of smaller than 1.68 (Table 3). Based on the metaregression analysis, factors of study location (Asia and Australia) and HOMA-IR ratio contributed to the heterogeneities. However, a large proportion of the heterogeneities could not be explained by the assessed variables. When focusing only on PCOS cases across studies, significant heterogeneity also existed $\left(\mathrm{I}^{2}=99.8 \%\right)$. The situation for only controls was the same $\left(\mathrm{I}^{2}=99.9 \%\right)$.

\section{Discussion}

We performed a systematic review and meta-analysis to assess the relationship between ghrelin level and PCOS. After summarizing all available evidence, we detected that ghrelin levels were significantly lower in PCOS patients than in controls. No publication bias was detected. Additionally, the finding was detected in many strata of subgroup analysis. These suggested that ghrelin might play a role in the pathogenesis of PCOS.

The association between ghrelin and PCOS risk is plausible. Besides the understanding of the relationship between ghrelin with insulin and blood glucose homeostasis as mentioned above, research has demonstrated a more direct linkage between ghrelin and ovarian function. For example, ghrelin has a negative effect on the hypothalamic-pituitary-ovarian axis [43] and is related to ovarian biosynthesis and/or action [33, 37]. Furthermore, ghrelin potentially regulate the secretion of androgens by ovary. It was suggested that the abnormal activity of corpus luteum in PCOS patients was also relevant to ghrelin [44]. Besides, ghrelin potentially affects proliferation, apoptosis and differentiation of granulosa and theca cells, which further triggers the hyperandrogenism in PCOS [44]. Aligned with these understanding, our meta-analysis summarizes evidence from human subject level studies and suggest the role of ghrelin in risk of PCOS. However, whether it is ghrelin that contributes to the risk of PCOS remains to be elucidated by further studies. For example, to avoid potential issues from reverse causality, further mendelian randomization studies assessing the association between ghrelin related genetic variants and PCOS risk are warranted to better characterize the relationship of interest.

To the best of our knowledge, this is the first comprehensive quantitative meta-analysis summarizing available evidence to determine the association between ghrelin level and PCOS. We conducted numerous subgroup analyses and meta-regression analysis based on several relevant factors to clarify the relationship. Our findings seemed to suggest that ghrelin might be associated with risk of PCOS. However, we should acknowledge that in subgroup analysis, not all strata suggested a significant association between ghrelin level and PCOS. Based on analysis of study location, only studies conducted in Europe revealed a significant association, while studies in other areas did not demonstrate such a relationship. Similarly, studies in which the measuring method is EIA did not suggest such a relationship. Additionally, studies in which HOMA-IR ratio is less than 2.12 and studies in which T-ratio is larger than 1.68 also demonstrated null associations. The meta-regression analysis suggests that study location (Asia and Australia) and HOMA-IR ratio contributed to part of the detected heterogeneities, suggesting that the inconsistent findings may be due to geographical differences, variability of PCOS relevant factors, as well as other factors in cases versus controls.

We noted considerable heterogeneity across studies for the overall pooled analysis. The high heterogeneity was not eliminated by the numerous subgroup analyses (Table 3 ). We think the heterogeneity may be relevant to variability in ethnicity of study participants, PCOS relevant factors like HOMA-IR ratio, as well as other factors not assessed in the current analysis, as suggested by the meta-regression analysis. We also should acknowledge that except for limited studies, in the majority of included studies there were limited numbers of involved participants. The pooled analysis in the current study was merely based on unadjusted results. Future large-scale studies evaluating the relationship between ghrelin level and PCOS after considering potential confounders are warranted to better characterize this issue. Furthermore, even though our analyses suggested an association between ghrelin level and PCOS risk, the clinical usage of this parameter in PCOS risk assessment and prediction may be limited, considering the significant variation of ghrelin level as detected.

In conclusion, after summarizing available evidence we identified that ghrelin levels were significantly lower in PCOS patients than in controls, suggesting a 
potential role of ghrelin in the development of PCOS. However, high heterogeneity was identified, besides inconsistent findings were suggested in subgroup analyses. Further studies with large sample size and consideration of relevant confounders are needed to better clarify the exact association between ghrelin levels and PCOS.

\section{Disclosure}

None of the authors have any potential conflicts of interest associated with this research.

\section{References}

1. Legro RS, Arslanian SA, Ehrmann DA, Hoeger KM, Murad MH, et al. (2013) Diagnosis and treatment of polycystic ovary syndrome: an Endocrine Society clinical practice guideline. J Clin Endocrinol Metab 98:4565-4592.

2. Azziz R, Marin C, Hoq L, Badamgarav E, Song P (2005) Health care-related economic burden of the polycystic ovary syndrome during the reproductive life span. J Clin Endocrinol Metab 90:4650-4658.

3. Pasquali R, Gambineri A, Pagotto U (2006) The impact of obesity on reproduction in women with polycystic ovary syndrome. BJOG 113:1148-1159.

4. Wild S, Pierpoint T, McKeigue P, Jacobs H (2000) Cardiovascular disease in women with polycystic ovary syndrome at long-term follow-up: a retrospective cohort study. Clin Endocrinol (Oxf) 52:595-600.

5. Diamanti-Kandarakis E, Alexandraki K, Protogerou A, Piperi C, Papamichael C, et al. (2005) Metformin administration improves endothelial function in women with polycystic ovary syndrome. Eur $J$ Endocrinol 152:749-756.

6. Dieguez C, Casanueva FF (2000) Ghrelin: a step forward in the understanding of somatotroph cell function and growth regulation. Eur J Endocrinol 142:413-417.

7. Delporte C (2013) Structure and physiological actions of ghrelin. Scientifica (Cairo):518909.

8. Murata M, Okimura Y, Iida K, Matsumoto M, Sowa H, et al. (2002) Ghrelin modulates the downstream molecules of insulin signaling in hepatoma cells. $J$ Biol Chem 277:5667-5674.

9. Andrews ZB, Liu ZW, Wallingford N, Erion DM, Borok E, et al. (2008) UCP2 mediates ghrelin's action on NPY/AgRP neurons by lowering free radicals. Nature 454:846-851.

10. Tong J, Prigeon RL, Davis HW, Bidlingmaier M, Kahn SE, et al. (2010) Ghrelin suppresses glucose-stimulated insulin secretion and deteriorates glucose tolerance in healthy humans. Diabetes 59:2145-2151.

11. Schöfl C, Horn R, Schill T, Schlosser HW, Muller MJ, et al. (2002) Circulating ghrelin levels in patients with polycystic ovary syndrome. J Clin Endocrinol Metab 87:4607-4610.

12. Orio F Jr, Lucidi P, Palomba S, Tauchmanova L, Cascella T, et al. (2003) Circulating ghrelin concentrations in the polycystic ovary syndrome. J Clin Endocrinol Metab 88:942-945.

13. Katulski K, Męczekalski B (2012) Ghrelin and fertility. Przeglad Menopauzalny 11:26-30. (In Polish)

14. Barber TM, McCarthy MI, Wass JA, Franks S (2006) Obesity and polycystic ovary syndrome. Clin Endocrinol (Oxf) 65:137-145.

15. Salehpour S, Broujeni PT, Samani EN (2008) Leptin, Ghrelin, Adiponectin, Homocysteine and Insulin Resistance Related to Polycystic Ovary Syndrome. IJFS 2:101-104

16. Vrbikova J, Hainer V (2009) Obesity and polycystic ovary syndrome. Obes Facts 2:26-35.

17. Wells GA, Shea B, O'Connell D, Peterson J, Welch V, et al. [cited 2015 August 30] The Newcastle-Ottawa Scale (NOS) for assessing the quality of nonrandomised studies in meta-analyses. Available from: http://www.ohri. $\mathrm{ca} /$ programs/clinical epidemiology/oxford.asp

18. Higgins JP, Thompson SG, Deeks JJ, Altman DG (2003) Measuring inconsistency in meta-analyses. BMJ 327:557-560.

19. Kuang D, Chen W, Song YZ, Yu YY, Zhang DY, et al. (2014) Association between the HSPA1B +/-1267A/G Polymorphism and Cancer Risk: a Meta-analysis of 14 Case-Control Studies. Asian Pac J Cancer Prev 15:6855-6861.

20. Higgins JP, Thompson SG (2002) Quantifying heterogeneity in a meta-analysis. Stat Med 21:1539-1558.

21. DerSimonian R, Laird N (1986) Meta-analysis in clinical trials. Control Clin Trials 7:177-188.

22. Egger M, Davey Smith G, Schneider M, Minder C (1997) Bias in meta-analysis detected by a simple, graphical test. BMJ 315:629-634.

23. Begg CB, Mazumdar M (1994) Operating characteristics of a rank correlation test for publication bias. Biometrics 50:1088-1101.

24. Arusoglu G, Koksal G, Cinar N, Tapan S, Aksoy DY, et al. (2013) Basal and meal-stimulated ghrelin, PYY, CCK levels and satiety in lean women with polycystic ovary syndrome: effect of low-dose oral contraceptive. J Clin Endocrinol Metab 98:4475-4482.

25. Bideci A, Camurdan MO, Yesilkaya E, Demirel F, Cinaz P (2008) Serum ghrelin, leptin and resistin levels in adolescent girls with polycystic ovary syndrome. J Obstet 
Gynaecol Res 34:578-584.

26. Cassar S, Teede HJ, Harrison CL, Joham AE, Moran LJ, et al. (2015) Biomarkers and insulin sensitivity in women with Polycystic Ovary Syndrome: Characteristics and predictive capacity. Clin Endocrinol (Oxf) 83:50-58.

27. Daghestani MH, El-Mazny A (2011) Circulating ghrelin levels and the polycystic ovary syndrome: correlation with the clinical, hormonal and metabolic features. Eur J Obstet Gynecol Reprod Biol 155:65-68.

28. Japur CC, Diez-Garcia RW, de Oliveira Penaforte FR, de Sa MF (2014) Imbalance Between Postprandial Ghrelin and Insulin Responses to an Ad Libitum Meal in Obese Women With Polycystic Ovary Syndrome. Reprod Sci 21:1020-1026.

29. Kale-Gurbuz T, Akhan SE, Bastu E, Telci A, Iyibozkurt AC, et al. (2013) Adiponectin, leptin and ghrelin levels in obese adolescent girls with polycystic ovary syndrome. J Pediatr Adolesc Gynecol 26:27-30.

30. Kun Shi K, Jasim BH, Shao X (2011) Evaluation of Ghrelin Levels in Polycystic Ovary Syndrome and the Correlation with Obesity, Insulin Resistance and Other Biochemical Features. Asian J Med Sci 3:218-222.

31. Mahde A, Shaker M, Al-Mashhadani Z (2009) Study of Omentin1 and Other Adipokines and Hormones in PCOS Patients. Oman Med J 24:108-118.

32. Micic D, Sumarac-Dumanovic M, Kendereski A, Cvijovic G, Zoric S, et al. (2007) Total ghrelin levels during acute insulin infusion in patients with polycystic ovary syndrome. J Endocrinol Invest 30:820-827.

33. Mitkov M, Pehlivanov B, Orbetzova M (2008) Serum ghrelin level in women with polycystic ovary syndrome and its relationship with endocrine and metabolic parameters. Gynecol Endocrinol 24:625-630.

34. Moran LJ, Noakes M, Clifton PM, Wittert GA, Le Roux CW, et al. (2007) Postprandial ghrelin, cholecystokinin, peptide YY, and appetite before and after weight loss in overweight women with and without polycystic ovary syndrome. Am J Clin Nutr 86:1603-1610.

35. Ozgen IT, Aydin M, Guven A, Aliyazicioglu Y. (2010) Characteristics of polycystic ovarian syndrome and relationship with ghrelin in adolescents. $J$ Pediatr Adolesc Gynecol 23:285-289.
36. Panidis D, Asteriadis C, Georgopoulos NA, Katsikis I, Zournatzi V, et al. (2010) Decreased active, total and altered active to total ghrelin ratio in normal weight women with the more severe form of polycystic ovary syndrome. Eur J Obstet Gynecol Reprod Biol 149:170174.

37. Panidis D, Farmakiotis D, Koliakos G, Rousso D, Kourtis A, et al. (2005) Comparative study of plasma ghrelin levels in women with polycystic ovary syndrome, in hyperandrogenic women and in normal controls. Hum Reprod 20:2127-2132.

38. Houjeghani S, Pourghassem Gargari B, Farzadi L (2012) Serum leptin and ghrelin levels in women with polycystic ovary syndrome:correlation with anthropometric, metabolic, and endocrine parameters. Int $J$ Fertil Steril 6:117-126.

39. Temel İ, Çelik Ö, Hascalik Ş, Çelik N, Şahin İ, et al. (2010) Serum nonesterified fatty acids, ghrelin, and homocysteine levels in women with polycystic ovary syndrome. Turk J Med Sci 40:221-228.

40. Wasko R, Komarowska H, Warenik-Szymankiewicz A, Sowinski J (2004) Elevated ghrelin plasma levels in patients with polycystic ovary syndrome. Horm Metab Res 36:170-173.

41. Zwirska-Korczala K, Sodowski K, Konturek SJ, Kuka D, Kukla M, et al. (2008) Postprandial response of ghrelin and PYY and indices of low-grade chronic inflammation in lean young women with polycystic ovary syndrome. J Physiol Pharmacol 59 Suppl 2:161-178.

42. Rotterdam ESHRE/ASRM-Sponsored PCOS Consensus Workshop Group (2004) Revised 2003 consensus on diagnostic criteria and long-term health risks related to polycystic ovary syndrome. Fertil Steril 81:19-25.

43. Van der Lely AJ, Tschop M, Heiman ML, Ghigo E (2004) Biological, physiological, pathophysiological, and pharmacological aspects of ghrelin. Endocr Rev 25:426-457.

44. Komarowska H, Wasko R, Iwanik K, Majewski P, Rafinska L, et al. (2006) Ghrelin ovarian cell expression in patients with polycystic ovary syndrome:an immunohistochemical evaluation. Horm Metab Res 38:783-788. 